\title{
Study on Fishery Commodities Cold Chain System at Malang City
}

\author{
${ }^{\mathrm{ab}}$ A.S.F.Q.R Mubarok, ${ }^{\mathrm{a}}$ A.W. Perdana, ${ }^{\mathrm{a} B . B}$. Sasmito, ${ }^{\mathrm{a}}$ B. Kusuma, ${ }^{\text {a.E. Waluyo, }}{ }^{\mathrm{c} M . T .}$ Aji, ${ }^{\mathrm{d}}$ S.T.M. Sulthoniyah \\ ${ }^{a}$ Fakultas Perikanan dan Ilmu Kelautan, Universitas Brawijaya \\ bCorresponding author: syihabfahmitip@ub.ac.id \\ ${ }^{\mathrm{c}}$ Fakultas Pertanian, Universitas Tidar Magelang \\ ${ }^{\mathrm{d}}$ Fakultas Pertanian, Universitas PGRI Banyuwangi
}

\begin{abstract}
Abtract
Fishery commodity distribution system has not been widely studied. Cold chain system must be applied in fishery product distribution system. The objective of this study was to evaluate the implementation of cold chain system in the traditional market in Malang City. The evaluation will be discussed more using a qualitative descriptive approach which was carried out with special research procedures related to the COVID 19 protocol. Qualitative data were taken by means of observations and interviews with respondents from fish mongers in traditional markets, Mlijo traders (mobile vegetable vendors) and consumers. The results showed that traditional markets are the sources of food supply in Malang City. The distribution chain shows that Mlijo traders play a major role in distributing fishery products directly to consumers. Consumers are very dependent on Mlijo traders in terms of purchasing daily food ingredients. The cold chain system has not been implemented well in traditional markets, while the cold chain system has been not applied by Mlijo traders.
\end{abstract}

Keywords: fishery, cold chain, system, malang

\section{Kajian Cold Chain System pada Komoditas Perikanan di Kota Malang}

\begin{abstract}
Abtrak
Komoditas perikanan merupakan salah satu komoditas yang belum banyak dikaji dalam sistim distribusinya. Cold Chain System merupakan suatu keharusan di dalam sistim distribusi produk perikanan. Penelitian ini bertujuan untuk mengevaluasi efektifitas penerapan cold chain system pada tingkat pedagang di pasar di kota Malang. Penelitian ini menggunakan pendekatan metode deskriptif kualilatif, yang dilaksanakan dengan prosedur penelitian khusus terkait dengan protocol COVID 19. Data kualitatif diambil dengan cara observasi dan wawancara kepada responden pedagang ikan di pasar tradisional, pedang Mlijo (tukang sayur keliling) dan konsumen. Hasil penelitian menunjukkan bahwa pasar tradisional merupakan salah satu sumber penyedia bahan pangan di Kota Malang. Rantai distribusi menunjukkan bahwa pedagang Mlijo berperan besar untuk mendistribusikan produk hasil perikanan secara langsung ke tangan konsumen. Konsumen sangat bergantung pada pedagang Mlijo dalam hal pembelian bahan pangan sehari-hari. Cold chain system belum terlaksana dengan baik di pasar tradisional, sedangkan cold chain system terputus pada pedagang Mlijo.
\end{abstract}

Keyword: perikanan, cold chain, sytem, malang

\section{PENDAHULUAN}

Komoditas perikanan telah menjadi suatu kebutuhan yang terus dibutuhkan oleh masyarakat. Ikan sebagai produk perikanan yang dipakai sebagai bahan baku merupakan jenis produk yang mudah rusak (perishable foods). Produk perikanan mudah rusak, sehingga perlu adanya suatu sistem untuk menjaga mutu bahan baku. Produk perikanan sebagai bahan baku mutlak untuk dijaga 
mutunya, sehingga di dalam pengolahan selanjutnya mampu menghasilkan produk bermutu baik [1]. Mutu produk perikanan mampu dijaga dengan menerapkan fish handling yang telah direkomendasikan oleh FAO. Salah satu prosedur yang ditetapkan FAO adalah penerapan cold chain system. Cold chain system yang diterapkan menggunakan es sebagai medium pendingin pada produk perikanan [2]. Penelitian ini bertujuan untuk mengevaluasi efektifitas penerapan cold chain system pada tingkat pedagang di pasar di kota Malang.

Cold chain system merupakan suatu usaha untuk menjaga mutu produk perikanan dalam sistem rantai pasok dengan menerapkan menjaga suhu dingin pada bahan baku produk perikanan. Cold chain untuk menjaga produk beku atau dingin dalam lingkungan dengan temperatur tertentu baik selama produksi, penyimpanan, transportasi, proses dan penjualan Terputusnya cold chain system berpengaruh besar terhadap mutu produk perikanan. Penerapan cold chain system yang belum efektif ditengarai terjadi pada tingkatan pedagang pasar, khususnya pasar tradisional [3]. Kajian mengenai mutu produk perikanan dan penerapan cold chain system di pedagang pasar mutlak diperlukan untuk evaluasi efektivitas penerapan cold chain system pada tingkat pedagang di pasar.

\section{METODE}

\section{Metode penelitian}

Penelitian dilakukan dengan metode kualitatif deskriptif disusun berdasarkan pengembangan metode dasar uji kualitatif menggunakan kuesioner dan observasi peneliti terhadap lingkungan. Kuesioner yang dikembangkan berdasarkan pada jenis produk perikanan yang dijual, mekanisme cold chain system yang dipakai dan asal produk perikanan. Pendekatan HCD (Human Centered Design) digunakan untuk mengetahui motif dari obyek penelitian [4].

\section{Responden}

Responden pertama adalah pedagang pasar dari pasar tradisional (Pasar Klandungan, Pasar Dinoyo, Pasar Besar Malang, Pasar Kebalenan, Pasar Gadang dan Pasar Induk Gadang) Kota Malang. Responden sampel dari 6 Pasar di Kota Malang diambil dari 26 lapak. Responden kedua merupakan pedagang Mlijo sebanyak 12 pedagang Mlijo. Responden ketiga adalah konsumen yang diambil sebagai sampel sebanyak 20 orang.

\section{HASIL DAN PEMBAHASAN}

\section{Analisis Situasi Pasar}

Pasar tradisional Kota Malang buka setiap hari, berdasarkan hasil wawancara didapatkan hasil bahwa pada hari-hari besar Pasar tetap 
buka akan tetapi okupasi lapak cenderung berkurang. Infrastruktur berupa lapak dengan standar minimal penjual ikan secara spesifik telah disediakan oleh pihak pengelola Pasar (Dinas Perindustrian dan Perdagangan Kota Malang) adalah Pasar Dinoyo, Pasar Besar Malang dan Pasar Gadang. Penyediaan lapak berbahan concrete dengan lapisan porselen telah dilakukan oleh Pemkot Malang, hal tersebut telah sesuai dengan spesifikasi lapak penjual ikan. Hal yang perlu diperhatikan adalah tipe pasar yang masih cenderung kearah "semi outdoor", belum baiknya sanitasi dan hygiene yang dipraktekkan dan belum disediakan ruangan khusus penjualan jenis daging. Ketiga hal diatas merupakan kekurangan yang harus diperbaiki kedepannya dalam pengembangan dan peningkatan mutu pasar sebagai pemenuh kebutuhan sehari-hari masyarakat Kota Malang. Pasar Klandungan, Pasar Kebalenan dan Pasar Induk Gadang juga telah dibangun beberapa insfrastrukturnya. Akan tetapi keberadaan pedagang ikan belum sepenuhnya tersentuh oleh pembangunan infrastruktur tersebut, karena masih berjualan di pinggiran pasar atau bahkan trotoar. Pedagang ikan yang dijumpai merupakan pedagang ikan yang menggunakan lapak dengan atap terpal dan tempat menampung ikan menggunakan ember dari plastik atau aluminium. Pengadaan kedua peralatan tersebut difasilitasi oleh pedagang ikan sendiri.
Kekurangan ketiga aspek tersebut diatas juga berlaku pada ketiga pasar ini.

Peran stakeholder terkait sangat diharapkan terhadap kebijakan pembangunan infrastruktur publik, khususnya pemerintah [5]. Standar sanitasi dan higiene mutlak di aplikasikan pada industri makanan dan minuman. Penerapan sanitasi dan higiene yang memadai mampu mengurangi risiko food hazard $[6,7]$.

\section{Perspektif Pedagang Pasar terhadap Cold Chain System}

Observasi lapang yang menunjukkan bahwa cara penyajian ikan pada lapak tidak menggunakan es. Penyimpanan ikan agar tetap segar sudah menggunakan styrofoam box atau fiber box yang telah diberikan es. Permasalahan muncul ketika ikan hendak diletakkan sebagai display, dimana ikan diletakkan pada tempat terbuka tanpa es. Hasil survei menunjukkan bahwa, $80 \%$ pengolah menempatkan ikan di dalam kantong kresek sesuai dengan ukuran ikan, tanpa penyertaan es pendingin dalam jumlah yang cukup.

Hal ini tentu berdampak pada penurunan mutu ikan. Jumlah es batu yang digunakan dalam proses pendinginan ikan harus tepat. Bila terlalu sedikit, proses pendinginan menjadi kurang baik sebab es batu dalam jumlah kecil tidak dapat terlalu lama mempertahankan suhu tetap rendah. Sebaliknya, penggunaan es batu secara berlebihan berarti suatu pemborosan 
[8], dan dengan perbandingan ikan dan es yang tepat perlu diperhatikan untuk mencari perlakuan yang efektif dengan meminimalkan penggunaan media pendingin pada penanganan ikan [9] .

Eksperimen yang dilakukan untuk mengetahui pola pemberian es oleh pedagang ikan di pasar dilakukan dengan membeli ikan dan menanyakan apakah bisa disertakan es ke dalam tempat ikan yang telah dibeli. Hasil eksperimen menunjukkan bahwa dari 16 kali pembelian ikan, 10 pedagang diantaranya memberikan es dan 6 lainnya tidak memberikan es. Pendalaman alasan pemberian es dilakukan dengan menanyakan langsung asal es, pedagang menyatakan bahwa es telah ada di dalam cool box dan styrofoam box yang dibawa sebagai tempat menyimpan ikan. Sehingga pemberian es dapat mudah dilakukan dengan mengambil sebagian es dari tempat penyimpanan ikan. Pedagang yang tidak memberikan es beralasan bahwa 5 diantaranya tidak membawa es dan 1 diantaranya mengaku kehabisan es dengan menunjukkan tempat penyimpanan ikan di dalam Styrofoam box. Penelitian mengenai efisiensi portable box untuk cold chain menyatakan bahwa penggunaan cold box dengan efisiensi pendinginan tinggi merupakan titik kritis terhadap keberhasilan cold chain system [10].

Eksperimen lain yang dilakukan adalah untuk mengetahui jenis produk perikanan yang dijual oleh pedagang ikan di pasar. Jenis produk perikanan di pasar dapat diklasifikasikan menjadi lima, yakni ikan air tawar, ikan air laut, pindang (ikan olahan), crustacean dan mollusk. Produk tersebut disediakan tergantung dengan musim dan supplier ikan. Ikan yang tersedia saat penelitian dilakukan dapat dilihat pada Tabel 1. Ikan yang dijual di pasar tradisional secara keseluruhan dijual dalam bentuk whole. Penelitian mengenai jenis produk perikanan yang dijual ke pasar, menyatakan bahwa jenis yang dijual tergantung pada musim. Kategori jenis ikan yang biasa dijual di pasar adalah jenis ikan demersal, ikan pelagis kecil dan ikan pelagis besar [11].

Hasil penelitian mengenai pengetahuan dan motif pedagang ikan akan pentingnya penggunaan es untuk menjaga mutu ikan menunjukkan bahwa pedagang ikan telah mengetahui secara pasti mengenai pentingnya es untuk menjaga kesegaran ikan, meskipun belum melaksanakan secara benar dan efisien. Konteks motif pedagang ikan mengenai pentingnya penggunaan es, hanya dilihat dari perspektif bahwa es mampu mempertahankan mutu ikan. Hal ini mengisyaratkan bahwa motif ekonomi sangat mendasari keputusan penggunaan es oleh pedagang. 
. Tabel 1. Komoditas produk perikanan di pasar tradisional Kota Malang

\begin{tabular}{|c|c|c|c|c|c|c|}
\hline \multirow[b]{2}{*}{ Komoditas } & \multicolumn{6}{|c|}{ Jumlah lapak di pasar yang menyediakan komoditas } \\
\hline & Kebalenan & Klandungan & $\begin{array}{c}\text { Induk } \\
\text { Gadang }\end{array}$ & Gadang & Besar & Dinoyo \\
\hline Bawal & & 1 & & 1 & & \\
\hline Gurami & & & 3 & & 5 & 2 \\
\hline Lele & 3 & 3 & 4 & 2 & 3 & 3 \\
\hline Nila & 2 & 2 & 4 & 1 & 4 & 2 \\
\hline Patin & & & & & & 1 \\
\hline Tombro & & 2 & 1 & & 3 & 1 \\
\hline Bandeng & 2 & 2 & & & & 1 \\
\hline Baronang & & 1 & & & & \\
\hline Cakalang & 1 & 1 & 3 & 2 & 2 & 2 \\
\hline Dorang & 1 & & & & & \\
\hline Julung-julung & 1 & 2 & & & & \\
\hline Kembung & 3 & 3 & 4 & 2 & 4 & 1 \\
\hline Kuniran & 1 & & & 1 & & 2 \\
\hline Kurisi & 1 & & 1 & 3 & 2 & \\
\hline Peperek & & 1 & & & 1 & \\
\hline Tengiri & 1 & 3 & & 2 & & \\
\hline Teri & & 1 & 1 & & 1 & \\
\hline Tongkol & 2 & 3 & 2 & 2 & & 1 \\
\hline Tuna & & 1 & 2 & & 3 & 1 \\
\hline Udang & 2 & 1 & 3 & 1 & 5 & 1 \\
\hline Kepiting & & & & & 1 & \\
\hline Rajungan & & & & & 1 & \\
\hline Cumi & & 1 & & 1 & 2 & \\
\hline Kerang & & 1 & & 1 & 3 & \\
\hline Pindang & 3 & 4 & 2 & 1 & 2 & 4 \\
\hline
\end{tabular}

\section{Perspektif Pedagang Mlijo terhadap Cold}

\section{Chain System}

Hasil penelitian menunjukkan bahwa pedagang Mlijo mengetahui penggunaan es diperlukan untuk menjaga kesegaran ikan. Pedagang Mlijo tidak menggunakan es ketika menjual dagangan ikan. Hal tersebut ditengarai karena tidak adanya motif mengenai urgensi penggunaan es oleh pedagang Mlijo. Asumsi pedagang Mlijo adalah karena barang dagangan berupa daging (ayam, sapi dan ikan) harus terjual pada hari yang sama, dimana pola penjualan keliling berlangsung selama 3-5 jam. Hal tersebut mendorong perilaku pedagang Mlijo untuk tidak menggunakan es ketika berjualan ikan. Penggunaan kresek plastik oleh pedagang sebagai tempat ikan dalam berjualan juga tidak memungkinkan untuk penambahan es. Sebagian kecil (3 orang) pedagang Mlijo menggunakan es untuk komoditas perikanan tertentu yang dianggap cepat mengalami penurunan mutu. Komoditas perikanan yang diberikan es oleh pedagang Mlijo tersebut adalah udang dan cumi. Es yang diberikan ke dalam kresek plastik didapatkan dari pedagang ikan (di pasar) tempat pedagang 
Mlijo membeli barang dagangan. Pedagang Mlijo secara keseluruhan berpendapat bahwa meminimalkan sisa dagangan yang dibawa ke rumah atau dalam kondisi tertentu apabila membawa sisa dagangan khususnya jenis dagangan daging akan langsung di bekukan (freezer) di dalam kulkas. Penelitian mengenai cold chain system di Perancis mengungkapkan bahwa aplikasi penggunaan kulkas sebagai alat pendingin masih menyisakan berbagai problematik yang perlu dipecahkan [10].

\section{Perspektif Konsumen terhadap Cold Chain}

\section{System}

Hasil penelitian menunjukkan bahwa konsumen lebih memilih ikan dengan mutu baik dengan cara visualisasi keseluruhan tubuh ikan, melihat kondisi insang dan bau, terlepas dari keberadaan es di dalam tempat ikan. Konsumen telah mengetahui bahwa suhu dingin berperan penting terhadap mutu komoditas perikanan, sehingga produk perikanan segar yang telah dibeli akan segera didinginkan (chiller) atau dibekukan (freezer) di dalam kulkas. Berbeda dengan temuan tersebut, konsumen lebih percaya dengan cara penilaian individu terhadap mutu ikan saat pembelian komoditas perikanan mengesampingkan pengetahuan pentingnya es untuk menjaga mutu ikan. Penelitian mengenai perilaku konsumen terhadap pembelian ikan di Turki menunjukkan bahwa hampir 50\% responden (konsumen ikan) kurang memperhatikan mengenai cold chain system yang dilakukan oleh pedagang, konsumen lebih memperhatikan pentingnya proses eviscerated [12].

\section{KESIMPULAN}

Hasil penelitian menunjukkan bahwa pedagang ikan baik pedagang ikan di pasar maupun mlijo belum melaksanakan cold chain system dengan efektif. Hasil analisis kualitatif dan kuantitatif merupakan pendekatan yang baik untuk mengetahui system cold chain system yang berlangsung di pasar. Pendekatan program diperlukan untuk menjaga kualitas dan food safety komoditas perikanan melalui akademisi maupun pemerintah.

\section{DAFTAR PUSTAKA}

[1]. Kusuma, B. Perdana, A.W., Astuti, R.T., Waluyo, E., Yufidasari, H.S. 2019. Tilapia (Oreochromis niloticus) Quality from Pasar Besar Malang. JADE, 2(1): 57-60.

[2]. Huss, H. 1995. Quality and quality changes in fresh fish. Food and Agriculture Organization of the United Nations. Rome, Italy. Diunduh dari http://www.fao.org/docrep/V7180E/V7 180E00.htm

[3]. Lestari, N., Yuwana, Efendi, Z. 2015. Identifikasi Tingkat Kesegaran dan Kerusakan Fisik Ikan di Pasar Minggu Kota Bengkulu. Jurnal Agroindustri, 5(1):44-56.

[4]. Salingaros, N.A. 2020. Connecting to the World: Christopher Alexander's Tool for Human-Centered Design. She Ji: The 
Journal of Design, Economics, and Innovation, 6(4): 455-481.

[5]. Hamzah, S., Adisasmita, S.A., Harianto, T., Pallu, M.S. 2014. Private Involvement in Sustainable Management of Indonesian Port: Need and Strategy with PPP Scheme. Procedia Environmental Sciences, 20: 187-196.

[6]. Rojas, E. 1995. Government-market interactions in urban development policy. Cities, 12(6): 399-400.

[7]. Abdul-Muthalib, N.A., Abdul-Rashid, M.F., Mustafa, S., Amin-Nordin, S., Hamat, R.A., Osman, M. 2012. Knowledge, attitude and practices regarding food hygiene and sanitation of food handlers in Kuala Pilah, Malaysia. Food Control, 27(2): 289-293.

[8]. Aminatuzzahra. Puwaningsih, R. Susanto, N. 2016. Simulasi Cold Chain System Pada Rantai Distribusi Ikan untuk Mengukur Peningkatan Mutu Ikan di Kota Semarang. Industrial Engineering Online Journal: Vol 5, No 4

[9]. Susanto, E., Agustini, T. W., Swastawati, F., Surti, T., Fahmi, A. S., Albar, M. F., dan Nafis, M. K. 2011. Pemanfaatan Bahan Alami untuk
Memperpanjang Umur Simpan Ikan Kembung (Rastrelliger neglectus). Jurnal Perikanan Universitas Gadjah Mada, 13(2), 60-69.

[10]. Du, J.,Nie, B., Zhang, Y., Du, Z., Wang, L., Ding, Y. 2020. Cooling performance of a thermal energy storage-based portable box for cold chain applications. Journal of Energy Storage, 28: 1-10.

[11]. Islamiyah, S., Arfiati, D., Subarijanti, H.U. 2010. Jenis-jenis Ikan yang di Daratkan di Pangkalan Pendaratan Ikan (PPI) Lekok Desa Jatirejo Kecamatan Lekok Kabupaten Pasuruan Jawa Timur. Prosiding seminar Nasional Ikan VI: 507-516.

[12]. Derens-Bertheau, E., Osswald, V., Laguerre, O., Alvarez, E. 2015. Cold chain of chilled food in France. International Journals of Refrigeration, 52: 161-167.

[13]. Mol, S., Akay, K.U., Guney, G.C. 2018. Seafood Safety at Home: Knowledge and Practice. International Journal of Gastronomy and Food Science, 13: 95100. 